\title{
Characterization of large genomic deletions in the FBN1 gene using multiplex ligation- dependent probe amplification
}

\author{
Larissa V Furtado ${ }^{1 *}$, Whitney Wooderchak-Donahue ${ }^{2}$, Alan F Rope ${ }^{3}$, Angela T Yetman ${ }^{4}$, Tracey Lewis ${ }^{2}$, Parker Plant ${ }^{2}$ \\ and Pinar Bayrak-Toydemir ${ }^{1,2}$
}

\begin{abstract}
Background: Connective tissue diseases characterized by aortic aneurysm, such as Marfan syndrome, Loeys-Dietz syndrome and Ehlers Danlos syndrome type IV are heterogeneous and despite overlapping phenotypes, the natural history, clinical manifestations and interventional course for each diagnosis can be quite unique. The majority of mutations involved in the etiology of these disorders are missense and nonsense mutations. However, large deletions and duplications undetected by sequencing may be implicated in their pathogenesis, and may explain the apparent lack of genotype-phenotype correlation in a subset of patients. The objective of this study was to search for large pathogenic deletions and/or duplications in the FBN1, TGF $\beta R 1$, and TGF $\beta R 2$ genes using multiplex-ligation dependent probe amplification (MLPA) in patients with aortopathy, in whom no mutations in the $F B N 1, T G F \beta R 1$, and TGF $\beta R 2$ genes were identified by sequencing.

Methods: The study included 14 patients from 11 unrelated families with aortic aneurysm. Of those, six patients (including 3 first-degree relatives), fulfilled the revised Ghent criteria for Marfan syndrome, and eight had predominantly aortic aneurysm/dilatation with variable skeletal and craniofacial involvement. MLPA for FBN1, TGF $\beta R 1$, and TGF $\beta R 2$ was carried out in all patients. A $385 \mathrm{~K}$ chromosome 15 specific array was used in two patients with a deletion of the entire FBN1 in order to define its size and boundaries.
\end{abstract}

Results: We identified two novel large deletions in the FBN1 gene in four patients of two unrelated families who met clinical diagnostic criteria for Marfan syndrome. One patient was found to have a FBN1 deletion encompassing exons 1-5. The other three patients had a $542 \mathrm{~Kb}$ deletion spanning the whole FBN1 gene and five additional genes (SLC24A5, MYEF2, CTXN2, SLC12A1, DUT) in the chromosome 15.

Conclusions: Our findings expand the number of large FBN1 deletions, and emphasize the importance of screening for large genomic deletions in connective tissue disorders featuring aortopathies, especially for those with classic Marfan phenotype.

\section{Background}

Thoracic aortic aneurysm with dissection is the most common fatal condition involving the aorta [1], and can be syndromic, familial nonsyndromic or sporadic. Mutations in genes related to the structure and function of the aortic wall, such as MYH11 on chromosome 16p12.2-13.3 [2,3], ACTA2 on chromosome 10q23-24 [4], SLC2A10 on

\footnotetext{
* Correspondence: larissa.furtado@hsc.utah.edu

'Department of Pathology, University of Utah Health Science Center, Salt Lake City, UT, 84108, USA

Full list of author information is available at the end of the article
}

chromosome 20q13.1 [5], NOTCH1 on chromosome 9q34-35 [6], TGFßR1 on chromosome 9q33-34 [7], and TGF $\beta R 2$ genes on chromosome 3p24-25 [8] have been linked to non-syndromic familial forms of thoracic aortic aneurysm [reviewed in 9]. Syndromic connective tissue diseases featuring aortic aneurysm and dissection comprise a heterogeneous group of genetic diseases, including Marfan syndrome (MFS; OMIM \# 154700), Loeys-Dietz syndrome (LDS; OMIM \# 609192), Ehlers Danlos syndrome type IV (EDS IV; OMIM \# 130050), and familial thoracic aneurysm syndrome (TAAD; OMIM\# 132900).
Ciomed Central 
Recently, a new syndrome presenting with aneurysms, dissections and tortuosity throughout the arterial tree and mild craniofacial features, early-onset osteoarthritis and skeletal and cutaneous anomalies was described to be associated with mutations in the SMAD3 [10]. These conditions have broad spectrum of phenotypic expression and overlapping phenotype, although their natural history and interventional course can be quite unique. Making the timely and correct diagnosis in individuals with connective tissue disorders with aortopathy is crucial to obtaining appropriate surveillance and interventions aimed at preventing the significant morbidity and mortality associated with these diseases. In this setting, molecular testing is a valuable adjunct to clinical assessment, especially in cases with non-classical phenotypes. The majority of syndromic connective tissue featuring aortopathy are caused by missense, nonsense or splice site mutations [11]. A few reports of large genomic deletions involving single and multiple exons of the FBN1 gene [12-17] as well as whole$F B N 1$ deletions [18-22] are available, although no large FBN1 duplications have been reported to date. Because of that, full gene sequencing is commonly the initial approach for the diagnosis of these patients. However, sequencing does not detect large exonic deletions or duplications unless quantitative methods are applied, which allegedly could explain the lack of genotype-phenotype correlation in some patients.

This study was undertaken to search for large pathogenic deletions and/or duplications in the FBN1, TGF $\beta R 1$, and TGF $\beta 22$ genes using multiplex-ligation probe amplification (MLPA) in 14 patients with clinical diagnosis of aortopathy in whom no mutations in the FBN1, TGF $\beta R 1$, and $T G F \beta R 2$ genes were identified by sequencing.

\section{Methods}

\section{Subjects}

Informed consent was obtained from patients and relatives using University of Utah and Primary Children's Medical Center Institutional Review Board-approved protocols. The study included 14 patients [10 males, 4 females; mean age: 21 years (age range: 2 - 43 years)] from 11 unrelated families, who had clinical diagnosis of aortic dilatation, aneurysm or aortic dissection and negative molecular analysis of the $F B N 1, T G F \beta R 1$, and TGF $\beta R 2$ genes by sequencing. In families with more than one affected individual, the result from mutational analysis was extrapolated to untested relatives. Of those, 6 patients (including 3 firstdegree relatives), fulfilled the revised Ghent criteria for diagnosis of Marfan syndrome [23], and 8 had predominantly aortic aneurysm or dilatation with variable skeletal and craniofacial involvement (Table 1). Data on the clinical phenotypes of patients were collected from medical records and during physical examinations during their visit to the Medical Genetics and Cardiology clinics at Primary Children's Medical Center.

Multiplex Ligation-dependent Probe Amplification (MLPA) Genomic DNA was extracted from peripheral blood using standard procedures (Gentra Puregene Blood Kit, Qiagen, Valencia, CA). MLPA assays were performed in duplicate according to the manufacturer's instructions [24]. The P065 and P066 Marfan Syndrome MLPA kits (MRCHolland, Amsterdam, The Netherlands) $[25,26]$ that contain probes for 54 of the 66 FBN1 exons and 7 TGF $\beta R 2$ exons, were used to detect deletions or duplications in FBN1. The P065 and P066 probemixes do not contain probes for $F B N 1$ exons: 1, 11, 12, 21, 23, 28, 33, 38, 40, 49, 52, 60, and for TGF $\beta R 2$ exon 2. P148 Loeys-Dietz MLPA kit (MRC-Holland, Amsterdam, The Netherlands) [27] was used to detect deletions or duplications in TGF $\beta R 1$ and TGF $\beta R 2$ genes. The P148 probemix contains probes for all exons of the TGF $\beta R 1$ and $T G F \beta R 2$ genes with the exception of TGF $\beta R 2$ exon 2. Amplification products from each MLPA assay were separated by capillary electrophoresis on an ABI 3100 Genetic Analyzer (Life Technologies, Carlsbad, CA, USA) and results were analyzed using GeneMarker ${ }^{\circledR}$ software version 1.6 (SoftGenetics, State College, PA, USA). Deletions and duplications of the targeted regions were detected when the height ratios of the fluorescent peaks were lower or higher than the normal height ratio range of $0.7-1.4$, respectively.

\section{Sequencing}

The coding exons and flanking intronic regions for TGF $\beta R 1, T G F \beta R 2$ and FBN1 were PCR-amplified for all patients. Primers sequences are available upon request. Amplicon fragments were bi-directly sequenced with universal M13 primers using the Big Dye ${ }^{\circledR}$ Terminator v3.1 cycle sequencing kit and an ABI 3730 DNA Analyzer (Life Technologies, Carlsbad, CA, USA). Sequences were compared to the TGF $\beta R 1$ and TGF $\beta R 2$ reference sequences (NM_004612.2 and NM_003242.5, respectively) and to the FBN1 reference sequence (NM_000138.4) using Mutation Surveyor software version 3.01 (SoftGenetics, State College, PA, USA).

In our Institution, we sequenced the TGF $\beta R 1$ and TGF $\beta R 2$ from seven patients, and the FBN1 gene from two patients. The remaining cases were sequenced at the Connective Tissue Gene Test (CTGT) Laboratory.

\section{Array-CGH 385 K Chromosome 15 Specific Array}

DNA from peripheral blood leukocytes from patients 2 and 3 was extracted using standard techniques (Gentra Puregene Blood Kit, Qiagen, Valencia, CA). One $\mu$ g of patients' DNA was labeled with 5'- Cy3 tagged nanomers while the female control was labeled with Cy5 nonamers 
Table 1 Summary of clinical profile of patients

\begin{tabular}{llllllllllllllll}
\hline & $\mathbf{1}$ & $\mathbf{2}^{*}$ & $\mathbf{3}^{*}$ & $\mathbf{4}^{*}$ & $\mathbf{5}$ & $\mathbf{6}$ & $\mathbf{7}$ & $\mathbf{8 \S}$ & $\mathbf{9 \S}$ & $\mathbf{1 0}$ & $\mathbf{1 1}$ & $\mathbf{1 2}$ & $\mathbf{1 3}$ & $\mathbf{1 4}$ \\
\hline Gender & $\mathbf{M}$ & $\mathbf{F}$ & $\mathbf{M}$ & $\mathbf{M}$ & $\mathbf{M}$ & $\mathbf{F}$ & $\mathbf{M}$ & $\mathbf{M}$ & $\mathbf{F}$ & $\mathbf{M}$ & $\mathbf{F}$ & $\mathbf{M}$ & $\mathbf{M}$ & $\mathbf{M}$ \\
\hline Age (years) & 27 & 42 & 15 & 12 & 42 & 19 & 12 & 30 & 2 & 15 & 25 & 18 & 14 & 27 \\
\hline
\end{tabular}

Aortic

Root dilatation $(Z \geq 2)$

Ao root surgery

Aneurysm

Dissection

Tortuosity

\section{Cardiac}

Mitral valve prolapse

Valve (other)

Cardiac (other)

Ophthalmologic

Ectopia lentis

\section{Skeletal}

Pectus carinatum

Pectus excavatum

Reduced US/LS

Increased arm/height

Scoliosis

Thoracolumbar kyphosis

Protrusio acetabuli

Pes planus

Hindfoot deformity

$\downarrow$ elbow extension

Wrist/thumb signs

Dural ectasia

\section{Craniofacial}

Hypertelorism

Bifid/broad uvula

Palate anomaly

Microretrognathia

Dolicocephalia

Craniosynostosis

Other

Skin

Striae

Thin and velvety skin

Easy bruising

Family History

\begin{tabular}{|c|c|c|c|c|c|c|c|c|c|c|c|c|c|c|}
\hline Ghent & + & + & + & + & + & - & - & - & - & - & - & - & - & + \\
\hline FBN1 sequencing & Neg & Neg & Neg & Neg & Neg & Neg & Neg & Neg & Neg & Neg & Neg & Neg & Neg & Neg \\
\hline$T G F \beta R 1 / 2$ sequencing & Neg & Neg & Neg & Neg & Neg & Neg & Neg & Neg & Neg & Neg & Neg & Neg & Neg & Neg \\
\hline
\end{tabular}

Abbreviations:

* Related patients: patient $2=$ mother; patients 3 and $4=$ sons.

$\S$ Related patients: patient $8=$ father; patient $9=$ daughter.

+: present; -: absent; blank spaces: information not available

Neg: Negative 
(Roche NimbleGen, Madison, WI). After purification by isopropanol precipitation, $6 \mu \mathrm{g}$ each of labeled patients and reference DNA were combined. The mixture was hybridized to a NimbleGen $385 \mathrm{~K}$ Chromosome 15 Specific Array for 16 hours at 42 degrees in a MAUI Hybridization System (BioMicro Systems). The array was then washed according to the manufacturer's recommendation (Roche NimbleGen, Madison, WI) and immediately scanned at 5 micron resolution. After scanning, fluorescence intensity raw data was extracted from the scanned images of the array using NimbleScan v2.5 software. For each of the spots on the array, normalized log2 ratios of the Cy3-labeled patient sample vs the Cy5-reference sample were generated using the SegMNT program. The data was visualized with Nexus v5.1 software (Biodiscovery, El Segundo, CA).

\section{Results}

In our study, we identified two novel large deletions in the FBN1 gene in four patients of two unrelated families who met clinical diagnostic criteria for Marfan syndrome. Of those, a novel FBN1 deletion encompassing exons 1-5 (Figure 1, Panel A) was identified in a 27-year-old male (patient 1; Tables 1 and 2) with dilated aortic root (3.99 $\mathrm{cm}, \mathrm{z}$-score of 3.76 ), mild tricuspid and mitral valve prolapse, tricuspid valve insufficiency, height $201 \mathrm{~cm}$ (6' 8") arm span $205.5 \mathrm{~cm}$ (6'10"), arachnodactyly, joint hypermobility, positive thumb and wrist signs, combined pectus carinatum/excavatum deformity of the anterior chest wall, and marked diffuse striae over the lower back and hips. Family history was remarkable for a diagnosis of Marfan syndrome in the mother, who died secondary to complications from surgery for aortic root dissection years prior, and one 30-year-old affected brother, who was unavailable for molecular testing.

The other large deletion was found in a family of a mother and two sons (patients 2, 3, and 4, respectively; Tables 1 and 2), who harboured a deletion of the entire $F B N 1$ gene. In those cases, all FBN1 probes and one control probe, located on the DUT (deoxyuridine triphosphatase) gene which is $301 \mathrm{~Kb}$ upstream from FBN1 exon 1 on chromosome 15q15-q21.1, were deleted (Figure 1, Panel B). A NimbleGen $385 \mathrm{~K}$ chromosome 15 specific array performed on patient 2 and 3 to refine the deletion size and boundaries revealed a $542 \mathrm{~Kb}$ deletion spanning bases chr15:46,208,030-46,750,218/Hg 18 Genome Build. This deleted region included 5 additional genes: SLC24A5, MYEF2, CTXN2, SLC12A1, and DUT (Figure 2). Clinically, patient 2 (mother), had a history of aortic valve replacement, and was status post Bentall procedure with a porcine valve in the setting of aortic dissection in 2005. She also had an abdominal aortic aneurysm. Skeletal involvement was characterized by a height of $190 \mathrm{~cm}\left(6^{\prime} 4^{\prime \prime}\right)$, arm span $197 \mathrm{~cm}\left(6^{\prime} 6^{\prime \prime}\right)$, pectus carinatum, arachnodactyly, and joint hypermobility. Patient 3 had aortic root $(3.72 \mathrm{~cm}$, z-score 3.22$)$ as well as ascending aortic $(2.69 \mathrm{~cm})$ dilation, height $193.5 \mathrm{~cm}$ (6'5"), arm span $198.2 \mathrm{~cm}\left(6^{\prime} 7^{\prime \prime}\right)$, pectus excavatum deformity, positive thumb sign, positive wrist sign, joint hypermobility, and striae over both legs. Ocular examination showed bilateral ocular lens subluxation. His younger brother (patient 4) had a dilated aortic root (3.7 $\mathrm{cm}$ of diameter, z-score of 5.7), bicuspid aortic valve, pectus excavatum deformity, arachnodactyly, significant joint laxity with positive thumb sign and positive wrist sign, marked pes planus with downward deviation of the medial malleolus, height greater than the 99th percentile for age, an arm span at $105 \%$ of height, hypertelorism, and high narrow palate.

In all other patients, including a 27-year-old male with classical Marfan syndrome phenotype (patient 14), no large deletions or duplications of the FBN1, TGF $\beta R 1$, and $T G F \beta R 2$ genes were identified.

\section{Discussion}

Only a few large FBN1 deletions involving single and multiple exons have been reported and have related to the most severe MFS phenotypes. Among those, deletions of exons 13-49 in mosaic [12]; deletion of whole exon 33 [12]; inframe deletions of exon 2 [17], exons 42-43 [13], exon 52 [17] and exons 60-62 [16]; deletions spanning exon 1 [14], in-frame deletion of exons 44-46 [13] and an out-of-frame deletion of exons 58-63 [15] were previously described. Increased phenotypic severity does not particularly apply to patients with complete $F B N 1$ deletions [18-22]. Recently, Hilhorst-Hofstee et al. (2010) [18] published a series of 10 patients with whole-FBN1 gene deletion presenting with phenotypes ranging from mild features of MFS to the classical MFS phenotype. In five of their patients, deletions extended beyond the FBN1 gene, spanning 1-9.4 Mb, including 9-46 genes. All of those deletions encompassed the same genes located upstream to the FBN1 as the ones involved in patient 2 and 3 of our cohort, although the breakpoints, size and position of the deletions differed between the two studies. Despite the additional deletion of five contiguous genes (SLC24A5, MYEF2, CTXN2, SLC12A1, DUT), our patients: 2, 3 and 4 had no other features than those that can be attributed to the deletion of FBN1. The same was observed in two patients from Hilhorst-Hofstee et al. [18] found to have deletion of 9 genes including FBN1. These findings not only support the role of haploinsufficiency of FBN1 in the pathogenesis of MFS, but also suggest that the function of SLC24A5, MYEF2, CTXN2, SLC12A1, DUT may not be impaired by complete loss of an entire allele.

Three additional patients with $15 \mathrm{q}$ deletions that included and extended beyond FBN1 were previously reported $[19,21,22]$. Their phenotype was characterized by marfanoid features predominantly affecting the skeletal 


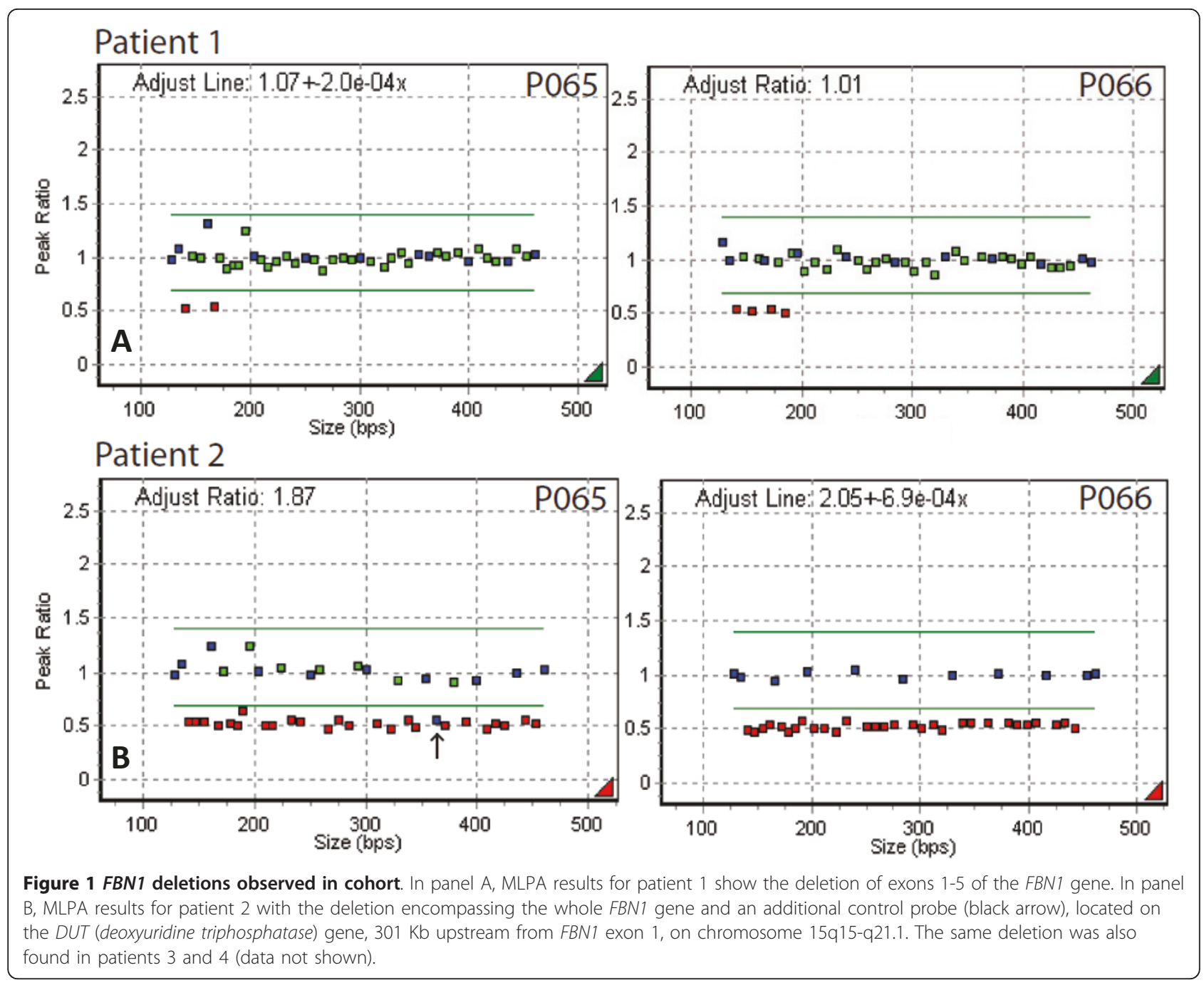

Table 2 MLPA Assay Results for FBN1, TGF $\beta R 1$, TGF $\beta R 2$ and COL3A1

\begin{tabular}{lc}
\hline Subjects & Deletion/Duplication Results \\
\hline Patient 1 & FBN1 exons 1-5 deletion \\
Patient 2 & FBN1 full gene deletion \\
Patient 3 & FBN1 full gene deletion \\
Patient 4 & Normal \\
Patient 5 & Normal gene deletion \\
Patient 6 & Normal \\
Patient 7 & Normal \\
Patient 8 & Normal \\
Patient 9 & Normal \\
Patient 10 & Normal \\
Patient 11 & Normal \\
Patient 12 & Normal \\
Patient 13 & Normal \\
Patient 14 &
\end{tabular}

system, with absent or mild aortic involvement. Psychomotor retardation and microcephaly was also described in two of those patients for whom the sizes and breakpoints of their 15 q deletions were unavailable [21,22]. The 16year-old female described by Faivre et al. [19] harboured a $15 \mathrm{q} 21.1 \mathrm{q} 21.2$ micro deletion of $2.97 \mathrm{Mb}$ that encompassed the entire $F B N 1$ and 12 additional genes, including the same genes as the ones involved in patient 2 and 3 of our cohort, although the breakpoints, size and position of the deletions differed between the two studies. As for our patients: 2, 3 and 4, no other features than those that can be attributed to the deletion of FBN1 were observed in their patient.

An important consideration is that all patients in our study, who harboured a FBN1 deletion, fulfilled the Ghent criteria for MFS with major manifestations in the skeletal and cardiovascular systems. This is especially remarkable given the relatively young ages of patient 3 


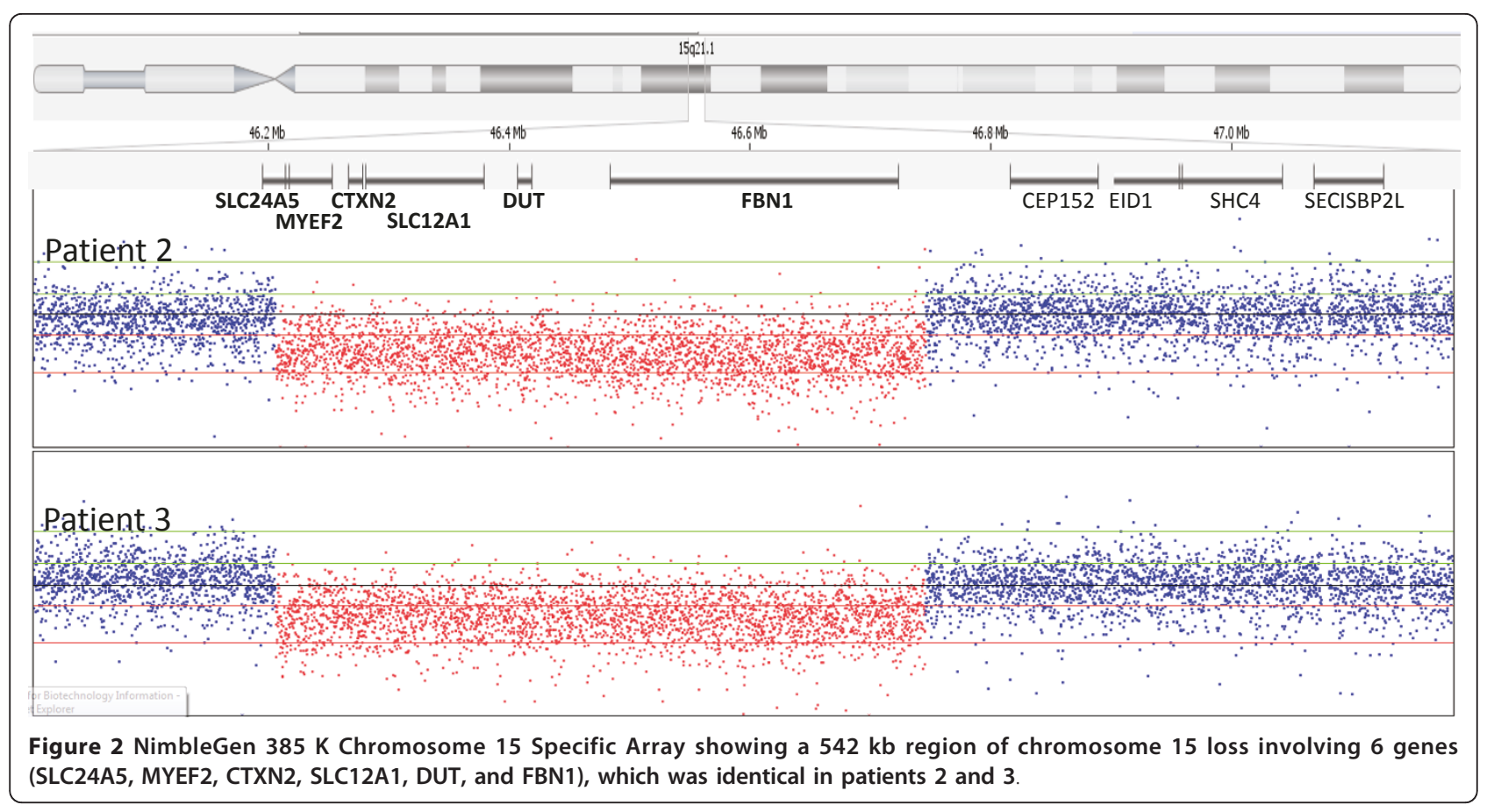

and 4, and suggests that the increased severity of MFS due to large FBN1 deletions may overcome the incomplete expression of MFS phenotype known to occur in children. In addition, the degree of severity and the distribution of the major manifestations differed among affected individuals, in keeping with the clinical variability seen in MFS, which in our patients, could be due to variable $F B N 1$ expression from the normal allele.

In our cohort, cases with non-classical phenotypes showed no large deletions and duplications in the genes targeted by MLPA. Technical limitations of available testing techniques, genetic heterogeneity and varied pathogenetic mechanisms involved in each of the connective tissue diseases with aortopathy may account for the lack of genotype-phenotype correlation in our subset of patients. For instance, commercially available kits for analysis of the FBN1 gene (P065 and P066) contain probes for 54 of the 66 FBN1 exons; and the probemix for TGF $\beta 22$ (P148) does not contain probes for exon 2. Therefore, a deletion or duplication of non-tested exons cannot be excluded leading to probable underreported deletions or duplications in this gene. Mosaicism and copy-number neutral rearrangements may also not be detected by MLPA. In addition, current molecular genetic testing of $F B N 1$, TGF $\beta R 1$, and TGF $\beta R 2$ genes, although powerful, may miss mutations in the promoter region or in other noncoding sequences. Another consideration is that genes, such as TGF $R$ R1and TGF $\beta 2$ may not harbour large deletions related to aortopathy with most of the reported TGF $\beta R 1$ and TGF $\beta R 2$ pathogenic mutations have been missense or splice site mutations
[11], with all but one lying in the kinase domain of those genes [28]. Recently, a de novo $14.6 \mathrm{Mb}$ duplication on chromosome $9 \mathrm{q} 22.32 \mathrm{q} 31.2$, comprising $T G F \beta R 1$ was found in a 17-year-old male with dysmorphic features, suggestive of LDS [29]. In contrast, no large deletions of $T G F \beta R 1$ and TGF $\beta 2$ have ever been reported in patients with aortopathy, which concurs with the findings from our dataset. Finally, the lack of genotype-phenotype correlation in some patients could be due to uncharacterized genetic elements in other loci, and as such, better evaluated by technologies targeting the whole genome or selected high-yield genes involved on aortopathies and Marfan-like phenotypes, such as MYH11, ACTA2, SLC2A10, NOTCH1 and FBN2 genes [9].

\section{Conclusions}

Our data expand the number of large FBN1 deletions, and emphasize the importance of screening for large genomic deletions in comprehensive genetic testing for connective tissue disorders featuring aortopathies, especially for those with classic phenotype of Marfan syndrome.

\section{Acknowledgements}

The authors sincerely thank the University of Utah Phenotyping Core for their support. We are grateful to all the patients and their relatives for participating in this study.

\section{Author details}

'Department of Pathology, University of Utah Health Science Center, Salt Lake City, UT, 84108, USA. ${ }^{2}$ ARUP Institute for Clinical and Experimental Pathology, Salt Lake City, UT, 84108, USA. ${ }^{3}$ Department of Pediatrics, Division of Medical Genetics, University of Utah Health Science Center, Salt Lake City, 
UT, 84108, USA. ${ }^{4}$ Department of Pediatrics, Division of Cardiology, Primary Children's Medical Center, Salt Lake City, UT, 84112, USA.

\section{Authors' contributions}

LVF participated in the design of the study, carried out part of the MLPA experiments, and wrote the manuscript; WWD carried out part of the MLPA experiments and performed the sequencing experiments; TL performed the array-CGH experiments in two patients; PP assisted WWD with sequencing experiments; AFR and AY were responsible for diagnosis and management of patients, participated in the design of the study and revision of the final manuscript; PBT conceived the study, and participated in its design and coordination. All authors read and approved the final manuscript.

\section{Competing interests}

The authors declare that they have no competing interests.

Received: 10 May 2011 Accepted: 21 September 2011

Published: 21 September 2011

\section{References}

1. Klein DG: Thoracic aortic aneurysms. J Cardiovasc Nurs 2005, 4:245-250.

2. Zhu L, Vranckx R, Khau Van Kien P, Lalande A, Boisset N, Mathieu F, Wegman M, Glancy L, Gasc JM, Brunotte F, Bruneval P, Wolf JE, Michel JB, Jeunemaitre $X$ : Mutations in myosin heavy chain 11 cause a syndrome associating thoracic aortic aneurysm/aortic dissection and patent ductus arteriosus. Nat Genet 2006, 38:343-349.

3. Khau Van Kien P, Mathieu F, Zhu L, Lalande A, Betard C, Lathrop M, Brunotte $F$, Wolf JE, Jeunemaitre $X$ : Mapping of familial thoracic aortic aneurysm/dissection with patent ductus arteriosus to 16p12.2-p13.13. Circulation 2005, 112:200-206

4. Guo DC, Papke CL, Tran-Fadulu V, Regalado ES, Avidan N, Bourgeois S, Estrera AL, Safi HJ, Sparks E, Amor D, Ades L, McConnell V, Willoughby CE, Abuelo D, Willing M, Lewis RA, Kim DH, Scherer S, Tung PP, Ahn C, Buja LM, Raman CS, Shete SS, Milewicz DM: Mutations in smooth muscle a-actin (ACTA2) lead to thoracic aortic aneurysms and dissections. Nat Genet 2007, 39:1488-1493.

5. Coucke PJ, Willaert A, Wessels MW, Callewaert B, Zoppi N, De Backer J, Fox JE, Mancini GM, Kambouris M, Gardella R, Facchetti F, Willems PJ, Forsyth R, Dietz HC, Barlati S, Colombi M, Loeys B, De Paepe A: Mutations in the facilitative glucose transporter GLUT10 alter angiogenesis and cause arterial tortuosity syndrome. Nat Genet 2006, 38:452-457.

6. Garg V, Muth AN, Ransom JF, Schluterman MK, Barnes R, King IN Grossfeld PD, Srivastava D: Mutations in NOTCH1 cause aortic valve disease. Nature 2005, 437:270-274.

7. Milewicz DM, Guo DC, Tran-Fadulu V, Lafont AL, Papke CL, Inamoto S, Kwartler CS, Pannu H: Genetic basis of thoracic aortic aneurysms and dissections: focus on smooth muscle cell contractile dysfunction. Annu Rev Genomics Hum Genet 2008, 9:283-302.

8. Hasham SN, Willing MC, Guo DC, Muilenburg A, He R, Tran VT, Scherer SE, Shete SS, Milewicz DM: Mapping a locus for familial thoracic aortic aneurysms and dissections (TAAD2) to 3p24-25. Circulation 2003, 107:3184-3190.

9. El-Hamamsy I, Yacoub MH: Cellular and molecular mechanisms of thoracic aortic aneurysms. Nat Rev Cardiol 2009, 12:771-786.

10. van de Laar IM, Oldenburg RA, Pals G, Roos-Hesselink JW, de Graaf BM, Verhagen JM, Hoedemaekers YM, Willemsen R, Severijnen LA, Venselaar $H$, Vriend G, Pattynama PM, Collée M, Majoor-Krakauer D, Poldermans D, Frohn-Mulder IM, Micha D, Timmermans J, Hilhorst-Hofstee Y, BiermaZeinstra SM, Willems PJ, Kros JM, Oei EH, Oostra BA, Wessels MW, BertoliAvella AM: Mutations in SMAD3 cause a syndromic form of aortic aneurysms and dissections with early-onset osteoarthritis. Nat Genet 2011, 2:121-126

11. The Human Gene Mutation Database at the Institute of Medical Genetics in Cardiff. [http://www.hgmd.cf.ac.uk/ac/index.php].

12. Blyth M, Foulds N, Turner C, Bunyan D: Severe Marfan syndrome due to FBN1 exon deletions. Am J Med Genet A 2008, 10:1320-1324.

13. Liu W, Schrijver I, Brenn T, Furthmayr H, Francke U: Multi-exon deletions of the FBN1 gene in Marfan syndrome. BMC Med Genet 2001, 2:11.

14. Mátyás G, Alonso S, Patrignani A, Marti M, Arnold E, Magyar I, Henggeler C, Carrel T, Steinmann B, Berger W: Large genomic fibrillin-1 (FBN1) gene deletions provide evidence for true haploinsufficiency in Marfan syndrome. Hum Genet 2007, 1:23-32.

15. Singh KK, Elligsen D, Liersch R, Schubert S, Pabst B, Arslan-Kirchner M Schmidtke J: Multi-exon out of frame deletion of the FBN1 gene leading to a severe juvenile onset cardiovascular phenotype in Marfan syndrome. J Mol Cell Cardiol 2007, 2:352-356.

16. Kainulainen K, Sakai LY, Child A, Pope FM, Puhakka L, Ryhänen L, Palotie A Kaitila I, Peltonen L: Two mutations in Marfan syndrome resulting in truncated fibrillin polypeptides. Proc Natl Acad Sci 1992, 89:5917-5921.

17. Loeys B, Nuytinck L, Delvaux I, De Bie S, De Paepe A: Genotype and phenotype analysis of 171 patients referred for molecular study of the fibrillin-1 gene FBN1 because of suspected Marfan syndrome. Arch Intern Med 2001, 161:2447-2454.

18. Hilhorst-Hofstee $Y$, Hamel BC, Verheij JB, Rijlaarsdam ME, Mancini GM, Cobben JM, Giroth C, Ruivenkamp CA, Hansson KB, Timmermans J, Moll HA, Breuning $\mathrm{MH}$, Pals $\mathrm{G}$ : The clinical spectrum of complete FBN1 allele deletions. Eur J Hum Genet 2010, 3:247-252.

19. Faivre $L$, Khau Van Kien $P$, Callier $P$, Ruiz-Pallares N, Baudoin C, Plancke A, Wolf JE, Thauvin-Robinet C, Durand E, Minot D, Dulieu V, Metaizeau JD, Leheup B, Coron F, Bidot S, Huet F, Jondeau G, Boileau C, Claustres M, Mugneret F: De novo 15q21.1q21.2 deletion identified through FBN1 MLPA and refined by $244 \mathrm{~K}$ array-CGH in a female teenager with incomplete Marfan syndrome. Eur J Med Genet 2010, 4:208-212.

20. Hiraki Y, Moriuchi M, Okamoto N, Ishikawa N, Sugimoto Y, Eguchi K, Sakai H, Saitsu H, Mizuguchi T, Harada N, Matsumoto N: Craniosynostosis in a patient with a de novo 15q15-q22 deletion. Am J Med Genet 2008, 11:1462-145

21. Adès LC, Sullivan K, Biggin A, Haan EA, Brett M, Holman KJ, Dixon J, Robertson S, Holmes AD, Rogers J, Bennetts B: FBN1, TGFBR1, and the Marfan-craniosynostosis/mental retardation disorders revisited. Am J Med Genet A 2006, 10:1047-1058.

22. Hutchinson S, Furger A, Halliday D, Judge DP, Jefferson A, Dietz $H C$, Firth $H$, Handford PA: Allelic variation in normal human FBN1 expression in a family with Marfan syndrome: a potential modifier of phenotype? Hum Mol Genet 2003, 18:2269-2276.

23. Loeys BL, Dietz HC, Braverman AC, Callewaert BL, De Backer J, Devereux RB, Hilhorst-Hofstee Y, Jondeau G, Faivre L, Milewicz DM, Pyeritz RE, Sponseller PD, Wordsworth P, De Paepe AM: The revised Ghent nosology for the Marfan syndrome. J Med Genet 2010, 7:476-485.

24. MLPA ${ }^{\circledR}$ DNA Detection/Quantification Protocol, version 29, 05-05-2010, MRC-Holland. [http://www.genycell.com/images/productos/protocolos/ p002_31.pdf].

25. MRC-Holland-SALSA MLPA kit P065 Marfan Syndrome-1. [http://www. mlpa.com/WebForms/WebFormProductDetails.aspx? Tag=tz2fAPIAupLo0TRBqtiGHA ||\&ProductOID=dLvyQjydEjk|].

26. MRC-Holland-SALSA MLPA kit P066 Marfan Syndrome-2. [http://www. mlpa.com/WebForms/WebFormProductDetails.aspx?Tag=tz2fAPIAupKyMjaDF \E\t9bmuxqlhe/Lgqfk8Hkjuss|\&ProductOID = 9qMCkc7Xu6c|].

27. MRC-Holland-SALSA MLPA kit P148 TGFBR . [http://www.mlpa.com/ WebForms/WebFormProductDetails.aspx?Tag=tz2fAPIAupKyMjaDF\E \t9bmuxqlhe/Lgqfk8Hkjuss|\&ProductOID=DTHYpQR $\backslash$ kEU|].

28. Drera B, Tadini G, Barlati S, Colombi M: Identification of a novel TGFBR mutation in a Loeys-Dietz syndrome type II patient with vascular EhlersDanlos syndrome phenotype. Clin Genet 2008, 73:290-293.

29. Breckpot J, Budts W, De Zegher F, Vermeesch JR, Devriendt K: Duplication of the TGFBR1 gene causes features of Loeys-Dietz syndrome. Eur J Med Genet 2010, 6:408-410.

\section{Pre-publication history}

The pre-publication history for this paper can be accessed here: http://www.biomedcentral.com/1471-2350/12/119/prepub

\section{doi:10.1186/1471-2350-12-119}

Cite this article as: Furtado et al: Characterization of large genomic deletions in the FBN1 gene using multiplex ligation-dependent probe amplification. BMC Medical Genetics 2011 12:119. 